\title{
Improving Disaster Risk Reduction Preparedness and Resilience Approaches in Emergency Response Interventions in African Countries
}

\author{
Ernest Tambo \\ Africa Disease Intelligence and Surveillance, Communication and Response (Africa DISCoR) \\ Institute, Yaoundé, Cameroon \\ Department Biochemistry and Pharmaceutical Sciences, Higher Institute of Health Sciences, Université des Montagnes, \\ Bangangté, Cameroon
}

\begin{abstract}
Article Info
Article history:

Received Mar 4, 2017

Revised May 8, 2017

Accepted May 22, 2017

\section{Keywords:}

Disaster

Emergency response

Hazard

Mitigation

Preparedness

Risk analysis

Surveillance

ABSTRACT

Increasing globalization, increasing intense urbanization and climate changes have been linked to communities' hazards and disasters vulnerabilities reported across Africa. Less data and information are documented on national to community disaster risk workforce readiness and resilience capacity in emergency humanitarian crises interventions. The lack of coherent and integrated disaster risk analysis and preparedness, response and recovery programs implementation is a major challenged in the region for decades. This paper highlights natural and man-made emergency hazards and disasters nature and exposure, potential approaches in Africa context. Our findings showed that man-made disasters events were the most documented, uneven in their nature, pattern and trend of occurrence and exposure consequences over time. Emerging and re-emerging outbreaks (Cholera, Polio, HIV, Ebola, Influenza, Rift Valley fever and Meningitis) were the most common, followed by conflicts and hunger, floods and land-sliding disproportionately spread across Africa. We also documented differential inadequacies in effective community risk assessment to emergency management, weak community disaster risk knowledge and attitudes to poorly integrated mitigation and recovery strategies. Leveraging on digital and social media network platforms advances coupled with existing fire, emergency facilities and proven effective hazard/disaster response lessons learnt and experiences are resources in strengthening laboratory capacity and laboratory networks, scaling up proactive displaced people/refugee security and safety standards support and best practice. Strengthening the national Sendai Framework for Disaster Risk Reduction (SDRRF) stewardship and investment (2015-2030) implementation is crucial in improving evidencebased, robust, and effective disaster risk reduction (DRR) community-based programs, in ensuring emergency public health readiness and resilient response capacities and ownership strategies in Africa.
\end{abstract}

Copyright (c) 2017 Institute of Advanced Engineering and Science. All rights reserved.

\section{Corresponding Author:}

Ernest Tambo,

Africa Disease Intelligence and Surveillance, Communication and Response Institute, Yaounde, Cameroon. Department of Biochemistry and Pharmacology, Université des Montagnes, Bangangt, Cameroon.

Email: tambo0711@gmail.com

\section{INTRODUCTION}

Africa region is regularly affected by a variety of disasters ranging from drought, to human conflict and population displacement in ensuring emergency public health preparedness and build resilient outbreaks and drought, famine, floods and conflicts to disaster risk reduction systems in settings [1, 2]. Very few peer- 
reviewed publications have assessed the variation in the extent and magnitude of hazard and disaster consequences associated emergency response remain poorly appraised and understood across Africa [2]. Yet, the region remains challenged with a variety of acute and extreme man and natural disaster conditions and impact such as outbreaks, extreme weather and climate changes, droughts and wildfire, coastal erosion, environmental and chemical hazards [3, 4]. However, the lack of inadequacy of finance and logistics, limited inter-sectorial collaboration and coordination, inadequate surveillance and lack of early detection/ reporting, lack of commitment, weak capabilities (performance, roles and experiences), weak health systems and lack personnel at the operational levels, and veterinary public health services as well as poor resources, lack of coherent risk assessment and emergency response plans [1, 3, 5]. Coordinated planning and response mechanisms, prudent budget allocation and legal frameworks for disaster management should be addressed by both local governments and key partners towards coherent and sustainable disaster preparedness and response programs and activities related drought, famine, floods and conflicts to outbreaks crises impact on human, animals and ecosystem.

Developing hazard and disaster surveillance and responsegoals and objectives, identify knowledge gaps inresponsecapabilities, and determine strategies for coordinated and sustainable local, national and regional response and resilienceactivities in line international health regulations core capacities and Human Rights [3, 5]. Understanding and establishing operational public health risk assessment and needs, and capacity development is imperative in developing, upgrading and standardizing preparedness and emergency response activities and guidelines. Supporting formal disaster risk graduate curriculum, training and retraining courses or workshops implementation is needed to enhance knowledge and practices in emerging threats and epidemics line with adopted WHO checklist covering hospitalpreparedness, equipment, workforce and surge capacity planning and best practices for public healthemergencies mitigation and resilience at all levels [6,7]. Fostering the implementation of "people-centered disaster risk-reduction" approach is vital to mitigate the impact of existing and future disasters crises through building preparedness and recovery pillars in enhancing peoples' or community awareness and resilient capacity to prepare for and withstand threats. Furthermore, strengthening disaster risk reduction (DRR) resilience competencies by integrating gender-based approach and concerns underscores all preparedness to recovery capabilities and interventions benefits in sustainable development across Africa communities [8]. Strengthening long-term disaster risk assessment and identification interventions such as emergency preparedness, response and recovery; mainstream risk reduction institutional and community-based capacity to real time threat surveillance and early warning systems (SEWS) is paramount. Nurturing governments and stakeholders commitment financial interment in disaster risk reduction preparedness and emergency response competencies is vital to address DRRimplementation workforce and facilities gaps, as key priority policy on national DRR resilience strategy in enhancing national and regional Disaster Risk Management (DRM) programs and actions plans [3, 9].

Strengthening community and public health hazard and disaster operational research, early community preparedness, awareness and health education, empowerment and resilience, planning and decision making policy in emergency capacity development and response initiative and programs are needed. Strengthening and sustaining public health laboratories surveillance and response systems including community-based early detection, risk communication and rapid response actions in hazards and disasters. Local, national/regional integrated hazard program resource and aptitude in emergency preparedness and response management, action plans and contingency measures in establishing 'risk-based surveillance' hot spots for zoonotic epidemics. Hence, building community disaster risk resilience and culture best practice in needed to strengthening disaster risk and outbreak preparedness and response in line with Africa Union (AU, 2063) and WHO/AFRO initiatives [10, 11].

This paper analyses the natural and man-made emergency disaster risk occurrence and pattern towards implementing robust, innovative and effective community-based disaster riskreduction emergency preparedness and response policies, resilient programs ownership and action plans in African countries.

\section{DEFINITION OF COMMON TERMS IN DISASTER RISK REDUCTION (DRR)}

Hazard: A potentially damaging physical event, phenomenon or human activity, which may cause the loss of life or injury, property damage, social and economic disruption or environmental degradation.

Risk: The probability of harmful consequences, or expected loss (of lives, people injured, property, livelihoods, economic activity disrupted or environment damaged) resulting from interaction between natural or human-induced hazards and vulnerable/capable conditions.

Disaster: A serious disruption of the functioning of a community or society causing widespread human, material, economic or environmental losses which exceed the ability of the affected community/society to cope using its own resources. 
Vulnerability: A set of conditions and processes resulting from physical, social, economic and environmental factors, which increase the susceptibility of a community to the impact of hazards.

Risk assessment: A process to determine the nature and extent of risk by analyzing potential hazards and evaluating existing conditions of vulnerability /capacity that could pose a potential threat or harm to people, property, livelihoods and the environment on which they depend.

Disaster risk reduction: The systematic development and application of policies, strategies and practices to minimize vulnerabilities and disaster risks throughout a society, to avoid (prevention) or to limit (mitigation and preparedness) adverse impact of hazards, within the broad context of sustainable development.

Mitigation: Structural and non-structural measures undertaken to limit the adverse impact of natural hazards, environmental degradation and technological hazards.

Resilience: The capacity of a system, community or society to resist or to change in order that it may obtain an acceptable level in function and structure. This is determined by the degree to which the social system is capable of organizing itself, and the ability to increase its capacity for learning and adaptation, including the capacity to recovery from a disaster.

Risk characterization: An important step when risk assessors integrate information from hazard and vulnerability analyses to indicate the extent to which probable conclusions about the disaster risk can be made from the information and analysis for communicating based on technical accuracy and any uncertainties, conflicts or alternative viewpoints to risk managers and other stakeholders'decision making and resource allocation process.

Risk communication: An iterative mainstreaming risk assessment in development, risk communication process of constant exchange among relevant parties with the intention of bringing congruence between actual, perceived and estimated risks among stakeholders as well as between the risk and development communities. The cultivation of a culture of risk prevention in both risk management and development undertakings depends critically on information and communication.

Risk management: The systematic management of administrative decisions, organization, operational skills and responsibilities to apply policies, strategies and practices for disaster risk reduction [12].

implementation against these epidemics in these countries. Meningococcal meningitis is still endemic with sporadic epidemics .in most middle belt countries of Africa from Senegal in the west to Ethiopia in the east. The most affected countries were: Burkina Faso (8.362 cases and 269 deaths), Niger (8.283 cases and 669 deaths), Nigeria (4.130 cases and 401 deaths), Ghana (1.614 cases and 226 deaths), Mali (1.174 cases and 67 deaths) Chad (1.248 cases and 51 deaths) and Ethiopia (1,306 cases and 96 deaths), South Sudan as well asDRC (10,629 cases and 901 deaths), Uganda (1,785 cases and 65 deaths). In 2016, 8 countries declared epidemics compared to 21 countries in 2005 (Burkina Faso, Burundi, South Sudan, Cote d'Ivoire, DRC, Ethiopia, Ghana, Mali, Niger and Chad) reported a total of 23,336 cases and 3,189 deaths in addition to HIV, malaria, dengue and polio outbreaks burden recurrence.

Furthermore, our findings documented varied frequency of genocide to Boko-Haram, Al-Shabab and extremists terrorism attacks in (Rwanda, Nigeria, Mali, Niger, Kenya and Somalia, Eretria and Djibouti, Burkina Faso, South Sudan and Libya), civil unrest and conflicts or political instability and insecurity, Gabon, Cameroon, DR Congo, Ivory coast, Nigeria, Egypt, Libya, Kenya). As well as reported increased disaster risk exposure associated impact on vulnerable populations across Africa and foreigners, flask floods episodes (Mozambique, Zambia, Zimbabwe and Malawi, Benin to land-sliding in Angola and Rwanda) and coastal water overflows in Atlantic and Pacific Oceans bordering African countries as shown in Table 1.

The WHO/AFRO, the United Nations technical assistance as well as Africa Union and its partners provide support to countries for the development of various tools for early disaster risk detection and mapping, analysis and reporting to effect timely response based on alert threshold. These include early disaster risk investigation; prompt risk alertness and consistent communication, local checklist of outbreak or disaster risk preparedness, routine/action plan for mass vaccination campaign and effective implementation. As well as step up and scale up logistics and contingencies strategies and measures altogether with humanitarian agencies and non-governmental organizations (NGOs) for rapid and efficient emergency disaster response and management actions plans. 
Table 1. Summary of Major Risk Disaster Crisis and Occurrence Pattern Over Time Across Africa

\begin{tabular}{|c|c|c|c|c|c|}
\hline & \multicolumn{5}{|c|}{ Major risk and disaster crisis across Africa } \\
\hline Africa region & $\begin{array}{l}\text { Drought/wildfire and } \\
\text { famine/hunger }\end{array}$ & $\begin{array}{l}\text { Political conflict, war } \\
\text { and mass } \\
\text { displacement }\end{array}$ & $\begin{array}{c}\text { Infectious } \\
\text { diseaseInfectious } \\
\text { diseases outbreaks } \\
\text { disaster }\end{array}$ & $\begin{array}{l}\text { Floods and } \\
\text { volcanic } \\
\text { eruption/ coastal } \\
\text { erosion }\end{array}$ & $\begin{array}{l}\text { Climate change } \\
\text { and global } \\
\text { warming }\end{array}$ \\
\hline $\begin{array}{l}\text { Central } \\
\text { Africa }\end{array}$ & $\begin{array}{l}\text { Moderate } \\
\text { (CAR, Chad, } \\
\text { Cameroon) }\end{array}$ & $\begin{array}{c}\text { High } \\
\text { (CAR, DRC, Congo, } \\
\text { Cameroon, Chad) }\end{array}$ & $\begin{array}{c}\text { High (Cholera, Malaria, } \\
\text { HIV, } \\
\text { Polio, Ebola, Meningitis, } \\
\text { Influenza) }\end{array}$ & $\begin{array}{c}\text { Low } \\
\text { (CameroonEquat } \\
\text { o rial, Guinea) }\end{array}$ & $\begin{array}{c}\text { High (Across } \\
\text { Africa) }\end{array}$ \\
\hline West Africa & $\begin{array}{c}\text { High } \\
\text { ( Niger, Nigeria, } \\
\text { Burkina Faso, Mali, } \\
\text { Sahel Sahara, }\end{array}$ & $\begin{array}{l}\text { High (Nigeria, Ivory } \\
\text { coast, Guinea, Mali, } \\
\text { Niger) }\end{array}$ & $\begin{array}{c}\text { High (Cholera, } \\
\text { Malaria, } \\
\text { HIV/TB, Polio, Lassa } \\
\text { fever, Ebola, Meningitis, } \\
\text { Influenza) }\end{array}$ & $\begin{array}{c}\text { Moderate } \\
\text { (Nigeria, } \\
\text { Benin, Senegal, } \\
\text { Ghana) }\end{array}$ & $\begin{array}{l}\text { High (Across } \\
\text { Africa) }\end{array}$ \\
\hline East Africa & $\begin{array}{l}\text { High (Djibouti, } \\
\text { Eritrea, Kenya, } \\
\text { Ethiopia, } \\
\text { Sudan, Madagascar) }\end{array}$ & $\begin{array}{l}\text { Moderate (Sudan, } \\
\text { South Sudan, } \\
\text { Burundi, Eritrea, } \\
\text { Somalia) }\end{array}$ & $\begin{array}{l}\text { High (Cholera, } \\
\text { malaria, HIV/TB, } \\
\text { Ebola, } \\
\text { Meningitis, Influenza) }\end{array}$ & $\begin{array}{l}\text { Moderate to } \\
\text { High }\end{array}$ & $\begin{array}{c}\text { High (Across } \\
\text { Africa) }\end{array}$ \\
\hline $\begin{array}{l}\text { Southern } \\
\text { Africa }\end{array}$ & $\begin{array}{l}\text { High } \\
\text { (Malawi, } \\
\text { Mozambique, } \\
\text { Zimbabwe, }\end{array}$ & $\begin{array}{c}\text { Moderate (Zimbabwe, } \\
\text { Malawi, } \\
\text { Mozambique, South } \\
\text { Africa) }\end{array}$ & $\begin{array}{c}\text { High Cholera, } \\
\text { HIV/TB, } \\
\text { Meningitis, Influenza) }\end{array}$ & $\begin{array}{l}\text { High (Malawi, } \\
\text { South Africa, } \\
\text { Zimbabwe ) }\end{array}$ & $\begin{array}{c}\text { High (Across } \\
\text { Africa) }\end{array}$ \\
\hline $\begin{array}{l}\text { Northern } \\
\text { Africa }\end{array}$ & $\begin{array}{l}\text { High (Mauritania, } \\
\text { Egypt, Libya, } \\
\text { Morocco) }\end{array}$ & $\begin{array}{l}\text { Moderate to High } \\
\text { (Libya, South Sudan, } \\
\text { Somalia, Sudan, } \\
\text { Egypt, Tunisia) }\end{array}$ & Low & Low & $\begin{array}{l}\text { High (Across } \\
\text { Africa) }\end{array}$ \\
\hline
\end{tabular}

\subsection{Public health emergency preparedness and response management stewardship and capabilities}

Owing to the increasing trend and patterns of public/community hazard and disaster consequences, improving public health emergency partnerships and investment opportunities to various stakeholders and community is crucial in building a culture of and capacity for disaster reduction and resilience in Africa [1, 2, 13]. These efforts are essential to prevent control and contain potential threats and disaster events engagement and commitment to scale emergency preparedness and response competency and capacity development. Implementing proactive public and community health surveillance and response partnership and coordination through early warning indicators and vigilance in both animal, human and environment risk factors and threats is needed. In such, well preparedhealth and environmentalsurveillance systems in improving planning for public health emergencies and coordination at local and regional levels should involve public health emergency response capability among service providers to enhance quick communication and better network in prevention and care services [14]. There is urgent need to accelerating the strategy's implementation within the Sendai Framework forDisaster Risk Reduction (SDRRF) post 2012 adopted of 10 year (Hyogo Framework for Action 2005-2015) comprehensive regional strategy for health disaster risk management (DRM) by 47 African member states commitments in achieving nine targets (expected to be achieved incrementally by 2014, 2017, and 2022) [1, 2]. These inter-sectoral and multidisciplinary strategies aimed at implementing sustainable and effective DRR and DRM institutional framework and actions plan; operational DRR competencies capacity for risk management; integration of relevant framework and capacity for risk assessment and mapping impact; fostering resilience culture and contextual interventions at all levels [1,4]. Strengthening health systems preparedness and emergency response management, and disasters recovery process; and, timely and evidence-based hazards and their impact on public health risk information dissemination and feedback is core.

Firming up sound DRR and DRM planning in all types of hazards preparedness and response capabilities and activities requires evidence and knowledge use in health and medical laws related to emergency management, including local, state and regional legislations to the International Health Regulations (IHR, 2005) and practice adherence. Local communities during emergencies and disasters policies, appropriate solutions and procedures implementation are need in complex disaster plans rampant across Africa [1]5, 16]. Contextual risk analysis inrisk/problem identification, analysis of needs is crucial in effective and timely development and implementation of integrated public health emergency preparedness and response plans and goals/strategies. Ensuring robust and coherent SDRRF nationwide planning and riskbenefits communication in strengthening generic capacities for resilience against all livelihood risks integration, coordination education, and recovery operations coupled with response exercises and drills training technical assistance and compliance with IHR, 2005 and Human Rights in achieving the sustainable development goals in Africa [17-19] as shown in Table 2. 
Table 2. Integrating Disaster Risk Assessment, Preparedness and Emergency Response in Sustainable Development Goals in Africa

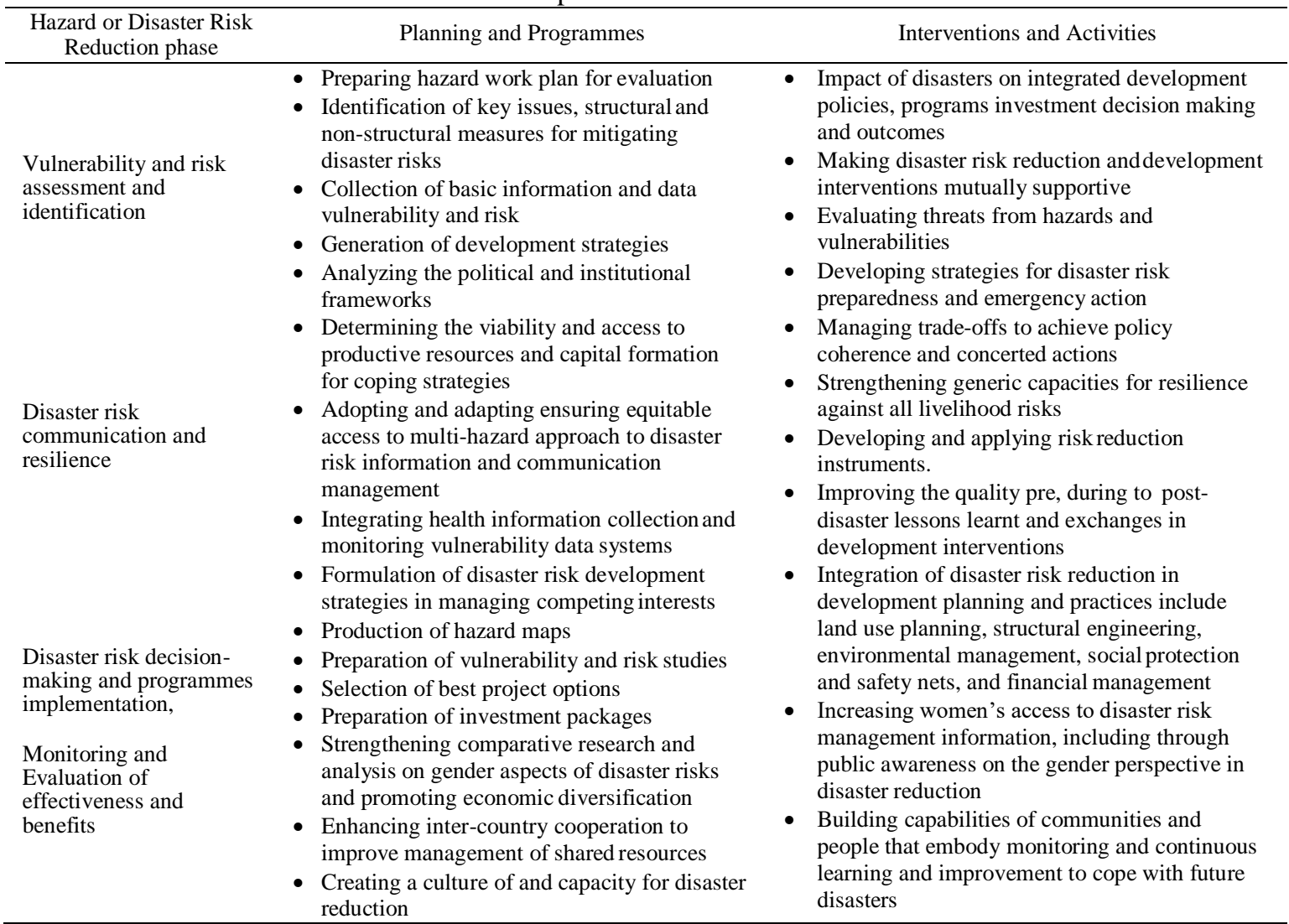

Leveraging on stakeholders technical assistance and training in establishing early warning indicators, epidemiologic and diagnostic laboratory data and information from medical charts and records is critical in droughts and famine/malnutrition to health systems programming and budgeting. Establishing and maintaining effective partnership and relationships coupled with accountable and transparent management by health managers, representatives of local medical and public health communities' officers, the media and the general public [18-20]. Generating rapid information to assist decision-makers in the event of a disaster managing crises and recognizes the capacity of capable citizens and community organizers to facilitate response and recovery if provided the opportunity and resources in tackling urgently and sustainably growing malnutrition and epidemics threat, and ecosystem degradation impact-related climate changes and global warming [21, 22]. Local information is a prerequisite for strategic and tactical statewide planning and managing crises and recognizes the capacity of capable citizens and community organizers to facilitate response and recovery if provided the opportunity and resources [24, 25]. Recognizing that public and global health security requires urgent attention, the significant individual and collective commitment and investment to avert direct and indirect health impacts is vital. Such effort can be achieved by providing evidence-based national and regional decision-makers in community roles by focusing on how best to forecast, prevent, respond, and recover public health disasters crises or emergency situations [1, 18], [23-25].

\subsection{Building community disaster risk reduction surveillance, emergency preparedness and response capacity}

Strengthening integrated community disaster risk reduction surveillance data and information collection and analysis can efficiently and effectively respond to potential to deliver an array of prevention and care services. Building capacity in Emergency preparedness and response management is needed in ensuring that the nation's health care systems have "surge capacity" the ability to respond to mass casualty events and adequately care [26, 27]. Functioning integrated public health laboratory in surveillance testing and screening; detection and early reporting of clinical case(s) and infection as well as providing timely public health preventive and control interventions and measures and quality outcomes [28]. Building operational level public health emergency surveillance and response capacity is capital in accurate and reliable diagnosis, evaluation and appropriate use of frontline, laboratory or point of care testing or screening 
of various biomarkers to assess the hazard and disease/epidemics burden in communities [29, 30]. Quality and rational patient management in any humanitarian or national program or interventions uptake in the allhazard approach rather than a scenario-based contingency planning can lead to the development of a standardized models and curriculum for training both in-service and pre-service DRR expertise and allied personnel [30, 31]. The risks and benefits of regional, country and local disaster management curriculum, capacity development programs and training activities integration into emergency programs in medical and paramedical schools and centers educational curriculum requires further evaluation across Africa.

Addressing operational public health emergency preparedness and response needs and challenges is needed in ensuring evidence priorities and tactics are periodically reset and communicated for developing and acquiring medical countermeasures, including food commodities and vaccines stockpile to respond rapidlyto emerging disaster or catastrophic situations [32-35]. Improving these alternative disaster risk reduction resilience strategies and counter-measures is critical such as establishing community-based DRR surveillance and resilience programs, accessible facilities and tools to rapidly logistics, local insourcing and supply chain provision such as (vaccines, PPE and contextual tools or regulation by laws). Importantly, the importance of risk data sharing reforms and regional platforms across African countries in emergency crisis should be established towards quality evidence in emergency interventions and outcomes metrics in Africa.

\subsection{Benefits of community-based early risk detection and communication, and rapid response actions}

In summary, globalization of trade and travel coupled with climate change and global warning continue to exacerbate disaster risk and has created interdependencies that render local disaster impacts in distant locations relevant to communities everywhere, such that risk is shared across national and institutional boundaries [34, 35]. The Sendai Framework DRR implementation offers a unique opportunity to move beyond simply responding to emergencies to a more comprehensive, prevention-based approach to management through the use of science and technical capabilities to improve social protection, people's healthy livelihood and productivity [1, 2], [36, 37]. Of note, the Sendai Framework promotes the strengthening of the science-policy interface and the development of links to other large global instruments (Sustainable Development Goals, climate change, and the International Health Regulations) [2, 7, 10, 23, 37].

Therefore, reducing disaster risk is a shared responsibility particularly where events or mass gatherings are enhanced by the advantages of globalization in terms of travel, interconnectivity of services, and supply chains [33, 36]. Implementing local DRR surveillance and early warning for evidence-based approach thatblend all-hazard risk readiness and management strategies is vital for the effectiveness and robustnessof agriculture, poverty alleviation andfood security, environmental and health security and safety (including infectious diseases and emerging epidemicsprevention and control) national and global initiatives benefits [38-41]. In practice, it will rely on the prospects and impact ofin country and cross country SDFDRR harmonization and integration into national priorities and strategic action plans across intergovernmental agreements, the International Health Regulations, the Sustainable Development Goals, and the UN Framework Convention on Climate Change and sustainable development goals (SDGs) in African countries [13, 4], [37-40], [42, 43].

\section{MOVING FORWARD DISASTERS RISK AND CRISES IMPACT MITIGATION AND RESILIENCE IN AFRICA}

Strengthening political commitment and institutional aspects, involving governance issues of policy and planning, legislation, organizational structures, resources, and, normative frameworks implementation; engaged leadership commitment, partnerships and investment decision-making.

- Building comprehensive and sustainable local/national risk analysis is needed in DRR hazard awareness projects and emergency response capabilities activities against existing and future threats and disasters costs

- Forecasting hazards and vulnerability impact assessment framework in sentinel or routine sites is necessary to gather DRR surveillance and early warning indices monitoring in strengthening effective and evidence-based mitigation, emergency preparedness programmes and response capabilities.

- Timely and accurate information on public health risk assessment on needs, issues and challenges is capital

- To prioritize capacity building, training and for effective community preparedness, refinement of plans, skills development and empowerment in implementation of real-time grid that reflected local/regional readiness and guidelines of how to improve efficient disaster risk preparedness and response system with end users' uptake and compliance. 
- Evaluation of formal and informal educational programs and training workshops that could rapidly prepare large numbers of health professionals working in hospitals and communities pre- and postdisaster impact recovery and management

- Addressing context-specific preparedness and response needs and challenges (socio-economic, medical and psychosocial, etc...) and innovative tactics against existing and furure disaster events locally and globally.

- Establishment of local and regional stockpiled network reliable and relevant DRR operational response plans and contingency measures.

Expanding proven effective response solutions and mechanisms to oversee local DRR educational programs and scenario training, and to ensure sufficient community access to protective equipment and materials stockpile in emergency events.

\section{CONCLUSION}

Implementation of real-time DRR framework and targets benefits is crucial and relies on improving government and regional leadership and investment on DRR surveillance data and early warning indices gathering and monitoring. This is critical in generating contextual data for quality evidence-based priorities, preparedness and emergency operational policies and programmes against evolving droughts and outbreaks, famine, flood and conficts consequences across Africa. Local community /regional readiness and resilience projects and technical assistance is essential to advance evidence-based, robust and efficient public health risk communication, disaster risk prediction strategies to emergency response system against current and future disaster situations, with continuous drills, quality monitoring and evaluation of programs effectiveness, performance and accountability competencies in improving disaster risk reduction preparedness and resilience approaches in emergency response interventions in Africa.

\section{ACKNOWLEDGMENT}

Thanks to Africa Disease intelligence and Surveillance Institute and Université des Montagnes for providing the enabling environment.

\section{REFERENCES}

[1] Olu O., et al., "Strengthening health disaster risk management in Africa: multi-sectoral and people-centred approaches are required in the post-Hyogo Framework of Action era," BMC Public Health, vol. 16, pp. 691, 2016.

[2] Downes E., "Nursing and complex humanitarian emergencies: Ebola is more than a disease," Nurs Outlook, vol/issue: 63(1), pp. 12-5, 2015.

[3] Levett J., "Disastrous events and political failures," Prehosp Disaster Med., vol/issue: 30(3), pp. 227-8, 2015.

[4] "The African Public Health Emergency Fund: stocktaking- report of the Secretariat," 2015.

[5] Reyers B., et al., "Navigating complexity through knowledge coproduction: Mainstreaming ecosystem services into disaster risk reduction," Proc Natl Acad Sci U S A, vol/issue: 112(24), pp. 7362-8, 2015.

[6] Hinton C. F., et al., "CDC Grand Rounds: Addressing Preparedness Challenges for Children in Public Health Emergencies," MMWR Morb Mortal Wkly Rep., vol/issue: 64(35), pp. 972-4, 2015.

[7] Norman I. D., et al., "A review of Ghana's 2009-2013 integrated strategic response plan for pandemic influenza: illustrative study of the perceived adequacy of preparedness for the pandemic influenza of sub-Sahara Africa," Emerg Med J., vol/issue: 30(5), pp. 388-92, 2013.

[8] :Sendai Framework for Disaster Risk Reduction 2015-2030," $2015 . \quad$ http://www. unisdr.org/files/43291_sendaiframeworkfordrren.pdf. Accessed 01 Oct 2016.

[9] Cancedda C., et al., "Strengthening Health Systems While Responding to a Health Crisis: Lessons Learned by a Nongovernmental Organization during the Ebola Virus Disease Epidemic in Sierra Leone," J Infect Dis., vol/issue: 15(214), pp. S153-S163, 2016.

[10] Bazeyo W., et al., "Institutional frameworks for management of epizoonotic emergencies in six countries in the EasternAfrica region: a situational analysis," East Afr J Public Health, vol/issue: 10(2), pp. 387-96, 2013.

[11] Stander M., et al., "Hospital disaster planning in the Western cape, South Africa," Prehosp Disaster Med., vol/issue: 26(4), pp. 283-8, 2011.

[12] Africa Office of the UN International Strategy for Disaster Reduction (UN/ISDR Africa, 2002), "Disaster risk reduction for sutainable development," 2002.

[13] Aliyu A., "Management of disasters and complex emergencies in Africa: The challenges and constraints," Ann Afr Med., vol/issue: 14(3), pp. 123-31, 2015.

[14] Li Z. J., et al., "A practical community-based response strategy to interrupt Ebola transmission in sierra Leone, 2014-2015," Infect Dis Poverty, vol/issue: 5(1), pp. 74, 2016.

[15] Carlos C., et al., "Hospital preparedness for Ebola virus disease: a training course in the Philippines," Western Pac Surveill Response J., vol/issue: 6(1), pp. 33-43, 2015. 
[16] Fan H. J., et al., "The Ebola threat: China's response to the West African epidemic and national development of prevention and control policies and infrastructure," Disaster Med Public Health Prep., vol/issue: 9(1), pp. 64-5, 2015 .

[17] Oleribe O. O., et al., "Nigerian response to the 2014 Ebola viral disease outbreak: lessons and cautions," Pan Afr Med J., vol/issue: 22(1), pp. 13, 2015.

[18] Pollard K. A., et al., "Development of a disaster preparedness curriculum for medical students: a pilot study of incorporating local events into training opportunities," Am J Disaster Med., vol/issue: 10(1), pp. 51-9, 2015.

[19] E. Tambo, et al., "Rift Valley Hemorrhagic Fever Epidemics in Niger Cross Border with Mali, West Africa," The Lancet Inf Dis., vol/issue: 16(12), pp. 1319-1320, 2016.

[20] Braman L. M., et al., "Climate forecasts in disaster management: Red Cross flood operations in West Africa, 2008," Disasters, vol/issue: 37(1), pp. 144-64, 2013.

[21] Canyon D. V., et al., "Managing Community Resilience to Climate Extremes, Rapid Unsustainable Urbanization, Emergencies of Scarcity, and Biodiversity Crises by Use of a Disaster Risk Reduction Bank," Disaster Med Public Health Prep., vol/issue: 9(6), pp. 619-24, 2015.

[22] Miller A., et al., "Integrating Health Research into Disaster Response: The New NIH Disaster Research Response Program," Int J Environ Res Public Health, vol/issue: 13(7), pp. E676, 2016.

[23] Bailey M. S., et al., "Bending the curve: force health protection during the insertion phase of the Ebola outbreakresponse," J R Army Med Corps., vol/issue: 162(3), pp. 191-7, 2016.

[24] Usman A., et al., "Recurrent cholera epidemics in Kano--northern Nigeria," Cent Afr J Med., vol/issue: 51(3-4), pp. 34-8, 2005.

[25] Bharti N., et al., "Remotely measuring populations during a crisis by overlaying two data sources," Int Health, vol/issue: 7(2), pp. 90-8, 2015.

[26] Mertens K., et al., "The direct impact of landslides on household income in tropical regions: A case study from the Rwenzori Mountains in Uganda," Sci Total Environ, vol. 550, pp. 1032-43, 2016.

[27] Kahindo M. J., et al., "Impact of mid-level management and support on the performance of a district health system in the Democratic Republic of the Congo," Med Trop (Mars), vol/issue: 71(2), pp. 147-51, 2011.

[28] Bazeyo W., et al., "Ebola a reality of modern Public Health; need for Surveillance, Preparedness and Response Training for Health Workers and other multidisciplinary teams: a case for Uganda," Pan Afr Med J., vol. 20, pp. 404, 2015.

[29] Almedom A. M., "Resilience research and policy/practice discourse in health, social, behavioral, and environmental sciences over the last ten years," Afr Health Sci., vol/issue: 8(1), pp. S5-13, 2008.

[30] E. Tambo, et al., "Rebuilding transformation strategies in post-Ebola epidemic in Africa," J. Infectious Diseases of Poverty, vol. 6, pp. 71.

[31] Derderian K., "Changing tracks as situations change: humanitarian and health response along the Liberia-Côte d'Ivoire border," Disasters, vol/issue: 38(4), pp. 673-89, 2014.

[32] Bazeyo W., et al., "Regional approach to building operational level capacity for disaster planning: the case of the Eastern Africa region," East Afr J Public Health, vol/issue: 10(2), pp. 447-58, 2013.

[33] Usher K., et al., "Strengthening and preparing: enhancing nursing research for disaster management," Nurse Educ Pract., vol/issue: 15(1), pp. 68-74, 2015.

[34] Norman I. D., et al., "A review of Ghana's 2009-2013 integrated strategic response plan for pandemic influenza: illustrative study of the perceived adequacy of preparedness for the pandemic influenza of sub-Sahara Africa," Emerg Med J., vol/issue: 30(5), pp. 388-92, 2013.

[35] Reusken C., et al., "Identification of essential outstanding questions for an adequate European laboratory response to Ebolavirus Zaire West Africa 2014," J Clin Virol, vol. 62, pp. 124-34, 2015.

[36] Andre M., et al., "Centers for Disease Control and Prevention (CDC). Assessing and mitigating the risks for polio outbreaks in polio-free countries - Africa, 2013-2014," MMWR Morb Mortal Wkly Rep., vol/issue: 63(34), pp. 75661,2014

[37] Kaiser R., et al., "The application of geographic information systems and global positioning systems in humanitarian emergencies: lessons learned, programme implications and future research," Disasters, vol/issue: 27(2), pp. 127-40, 2003.

[38] Lutge E., et al., "A hospital based surveillance system to assess the burden of trauma in KwaZulu-Natal Province South Africa," Injury, 2015.

[39] Stein C., et al., "Meeting national response time targets for priority 1 incidents in an urban emergency medical services system in South Africa: More ambulances won't help," S Afr Med J., vol/issue: 105(10), pp. 840-4,2015.

[40] E. Tambo, et al., "Strengthening community emergency preparedness and response in threats and epidemics disasters prevention and management in Saudi Arabia," Intl J Emergency Medicine, vol/issue: 13(3), pp. 288-298, 2017.

[41] Fähnrich C., et al., "Surveillance and Outbreak Response Management System (SORMAS) to support the control of the Ebola virus disease outbreak in West Africa," Euro Surveill, vol/issue: 20(12), 2015.

[42] Smith M. J. and Silva D. S., "Ethics for pandemics beyond influenza: Ebola, drug-resistant tuberculosis, and anticipating future ethical challenges in pandemic preparedness and response," Monash Bioeth Rev., vol/issue: 33(2-3), pp. 130-47, 2015.

[43] Orach C. G., et al., "Performance of district disaster management teams after undergoing an operational level planners' training in Uganda," East Afr J Public Health, vol/issue: 10(2), pp. 459-68, 2013. 


\section{BIOGRAPHIES OF AUTHORS}

Dr Tambo is a Disease Surveillance Specialist at Africa Disease intelligence and Surveillance Institute and Pharmacologist Lecturer at Université des Montagnes. After two postdoctoral fellowships in China, CDC \& WHO collaborating Centre in tropical Disease Research, Shanghai and University of Pretoria, South Africa, he has gained sound and wide in-depth expert knowledge, skills and experiences as Senior Scientist and regional coordinator, project manager to technical advisor and consultant in local and international funded projects (quantitative and qualitative studies) in China, Africa and Middle East regions. With experiences in public health and management, promoting smart and evidence healthcare delivery and best quality while monitoring and providing capacity building, partnerships and targeted investment added-value remains of great importance in improving the quality of life and wellbeing of populations, economic transformation and sustainable development. Dr Tambo has over 14 years of teaching and research experiences in supporting academia, policy-makers and health systems implementers including capacity building of junior personnel to undergraduate and postgraduate students, mentorship and supervision. There is no doubt; the current article fosters disaster risk assessment and evidence DRR practice and resilience as well as research and development(R\&D) across Africa and globally in guiding evidence-based DRR decision policy and programs. Dr Tambo has over 60 peer-reviewed publications ininternational journals. 